\title{
CHROMATOGRAPHIC AND ELECTROPHORETIC SEPARATION OF PLATELET-CLUMPING SUBSTANCE IN RABBIT PLASMA
}

\author{
Hiroh Yamazaki, Hiroshi Murase, Tatsuo Shimamoto, \\ Hagano IJIRI, Koichi ANAN AND Takio ShImamoto \\ Institute for Cardiovascular Diseases, School of Medicine, \\ Tokyo Medical and Dental University, Yushima, Tokyo
}

The authors previously reported that platelet-clumping substance (SHIMAMOTO and YAMAZAKI, 1958) ${ }^{1)}$ was detected in heparinized plasma from rabbits administered adrenaline or high molecular weight substance such as agar solution and bacterial endotoxin by an intravenous injection. ${ }^{2}$ The plateletclumping substance also came to be observed in vitro after weak acidification of plasma in the presence of calcium ions. ${ }^{3)}$ Though its chemical structure is still obscure, the platelet-clumping substance has properties different from those of adenosine-diphosphate (ADP), thrombin, fibrinogen, adrenaline, serotonin, thrombocyte agglutinating factors ${ }^{4)}$ or ADP cofactor. ${ }^{5)}$ A similar substance was also found in the plasma of patients suffering from acute infectious diseases or thrombosis ${ }^{6)}$ and the substance might be related to thrombi-formation in various morbid conditions. So the authors are investigating analysis of the platelet-clumping substance for the genesis of thrombosis and in the present experiments some chemical properties of the platelet-clumping substance of rabbits were studied using column chromatography and electrophoresis.

\section{MATERIALS AND METHODS}

\section{SAMPLE PREPARATION}

Thirty two male rabbits weighing 2.0 to $2.8 \mathrm{~kg}$ were used. Twenty one rabbits were bled and the blood was collected for use as a non-treated sample. The blood of the other eleven rabbits received intravenous injections of $0.5 \%$ agar-saline solution (Agar-noble, Nihon Eiken Co., Ltd.) at a dosage of $5 \mathrm{ml} / \mathrm{kg}$ was then collected 30 minutes after the injection.

Under light anesthesia (urethane, $1.2 \mathrm{~g} / \mathrm{kg}$ i.p.), about $80 \mathrm{ml}$ of blood was drained from a carotid artery by way of polyethylane tubing into a siliconized tube containing

Received for publication June 26, 1969

山崎博男, 村瀬 弘, 島本達夫, 井尻はがの, 阿南功一, 島本多喜雄 
heparin sodium (50 units $/ \mathrm{ml}$ ). The blood was collected for preparation of a plateletpoor plasma. In 10 plasma samples out of the 21 non-treated samples the $\mathrm{pH}$ was adjusted to 5.5 (pH meter, model HM 5A, Tōa Denpa Co., Ltd.) with dilute $\mathrm{HCl}$ at room temperature. The samples were centrifuged at $1,000 \mathrm{~g}$ for 5 minutes to exclude precipitates. Each heparinized plasma collected from the non-treated and the agarinjected rabbits, and the acidified heparinized plasma collected from the non-treated rabbits were subjected to chromatography and electrophoresis at $4^{\circ} \mathrm{C}$ as follows.

\section{COLUMN PREPARATION AND ELUTION SCHEDULE}

\section{Gel Filtration Column Chromatography}

About $20 \mathrm{~g}$ of Sephadex G-25, G-50 and G-200 (Pharmacia, Uppsala, Sweden) was used. The mediums used were $0.02 \mathrm{M}$ phosphate buffer, pH 6.6, for $\mathrm{G}-25$ and $\mathrm{G}-50$, and $0.02 \mathrm{M}$ phosphate buffer, $\mathrm{pH} 7.0$, containing $0.5 \mathrm{M} \mathrm{NaCl}$, for G-200. Plasma was dialyzed against the respective buffer for 72 hours, centrifuged at $1,000 \mathrm{~g}$ for $15 \mathrm{~min}$ utes, and $10 \mathrm{ml}$ of each supernatant was applied to a column $(2.5 \mathrm{~cm}$ in diameter). The eluate was monitored at $280 \mathrm{~m} \mu$ by an ultraviolet absorption scanner (Yamakawa Product Co., Ltd., Tokyo, Japan), collected in $15 \mathrm{ml}$ portions by a fraction collector (Tōyō Science Indust. Co., Ltd., Tokyo, Japan) and examined for platelet-clumping activity. The eluate from Sephadex G-200 chromatography was diluted 3-fold with distilled water prior to the test for clumping activity. Meanwhile the absorption curve of each active fraction in the ultraviolet region was measured by a recording spectrophotometer (Shimazu Product. Co., Ltd., Kyoto, Japan).

\section{Ion-Exchange Column Chromatography}

About $20 \mathrm{~g}$ of DEAE-cellulose $(0.92 \mathrm{meq} / \mathrm{g}$ standard absorbent capacity, Brown, U.S.A.), equilibrated with $0.02 \mathrm{M}$ phosphate buffer, $\mathrm{pH} 6.0$, was used. Plasma was dialyzed and centrifuged to exclude precipitates. Then $10 \mathrm{~m} 1$ of each supernatant was applied to the column. It was then eluted with the same buffer containing stepwise increments in the $\mathrm{NaCl}$ concentration $(0.07,0.4$ and $1.5 \mathrm{M})$. The eluate was monitored for its protein concentration as described before and each eluate $(15 \mathrm{ml})$ examined for platelet-clumping activity.

\section{DEAE-Sephadex A-50 Column Chromatography}

Dialyzed plasma $(10 \mathrm{ml})$ was chromatographed on a column of about $20 \mathrm{~g}$ DEAESephadex A-50 (medium grade, Pharmacia, Uppsala, Sweden) equilibrated with $0.02 \mathrm{M}$ phosphate buffer, $\mathrm{pH}$ 6.6, and eluted in a stepwise manner with the same buffer containing $0.07,0.17$ and $0.38 \mathrm{M} \mathrm{NaCl}$. The platelet-clumping activity and the absorption at $280 \mathrm{~m} \mu$ of the eluates were measured as described above.

The active fractions obtained by the three methods of column chromatography (II. 1,2 and 3) were separately dialyzed in a cellulose tubing (Visking Co., U.S.A.) against running water for 72 hours and lyophilized for further experiments.

\section{ELECTROPHORETIC PROCEDURES}

\section{Starch-Block Electrophoresis}

Starch-block electrophoresis was performed according to the method of KUNKEL and SLATER ${ }^{7}$. Plasma $(5 \mathrm{ml})$ was placed at the starting line of a plastic tray, $26(\mathrm{~L})$ $\times 30(\mathrm{~W}) \times 1(\mathrm{H}) \mathrm{cm}$, filled with hydrolysed starch (Connaught Medical Research Lab., University of Toronto, Toronto, Canada), that had been repeatedly washed with distilled 
water and then mixed with veronal buffer, ionic strength 0.05, pH 8.6. Electrophoretic separation of the material was carried out at $4^{\circ} \mathrm{C}$ with a potential gradient of $5.0 \mathrm{~V} / \mathrm{cm}$ for 16 hours. Bromphenol blue dye solution was mixed with the sample to serve as an indicator of albumin migration. After electrophoresis the starch block was cut into 1 $\mathrm{cm}$ segments beginning at the starting line. Each segment was named $1 \mathrm{~cm}$-fraction ( $0-1 \mathrm{~cm}$ from origin), $2 \mathrm{~cm}$-fraction (1-2 cm from origin) and so on, and placed in a test tube to mix with $1.0 \mathrm{ml}$ of physiological saline. The mixture was agitated 100 times using a bamboo stick. The mixture stood for 30 minutes at $4^{\circ} \mathrm{C}$ and then the supernatant was examined for platelet-clumping activity. The supernatant was dialyzed against running water for 72 hours and lyophilized for further experiments.

\section{Immunoelectrophoresis}

Immunoelectrophoresis in agar-gel was carried out according to the method of SHEIDEGGER ${ }^{8)}$ to identify the plasma component of the active fraction from the starch block. Goat antiserum to rabbit serum (Hyland Lab., Los Angeles, Calif., U.S.A.) was used as the antibody.

\section{Paper Electrophoresis}

Cellulose acetate membrane (Separax, Jōkō Indust. Co., Ltd., Tokyo, Japan) electrophoresis was made on paper electrophoresis equipment (Jōkō Indust. Co., Ltd., Tokyo, Japan) according to the method described by ARONSSON and GRöNwALL ${ }^{9)}$. Veronal buffer, $\mathrm{pH} 8.6, \mu=0.06$, was generally employed. Ponceau $3 \mathrm{R}$, nigrosin $\mathrm{B}$, alcian blue and toluidine blue were used for staining.

\section{ASSAY FOR PLATELET-CLUMPING ACTIVITY}

The method was essentially the same as reported previously ${ }^{2,3)}$. Blood was collected from healthy male rabbits weighing 2.2 to $2.9 \mathrm{~kg}$. Disodium ethylendiamine tetraacetate (EDTA) (final concentration: $0.1 \%$ ) was used as an anticoagulant. The blood was centrifuged at $100 \mathrm{~g}$ for 30 minutes at $4^{\circ} \mathrm{C}$. The resulting supernatant (platelet-rich plasma) was then centrifuged at $1,000 \mathrm{~g}$ for 15 minutes at $4^{\circ} \mathrm{C}$ and platelets in the sediment layer were washed twice with physiological saline and then resuspended in saline of one half of the volume of the original blood sample. The $\mathrm{pH}$ of the saline was adjusted to 7.4-7.6 with a dilute $\mathrm{NaHCO}_{3}$ solution. The washed platelet suspension $\left(7 \times 10^{5}-10 \times 10^{5} / \mathrm{mm}^{3}\right)$ showed no spontaneous clumping under microscopic examination. Meanwhile platelet-rich plasma was collected using sodium citrate (final concentration: $0.38 \%$ ).

One drop of the sample was mixed one drop of the normal platelet-saline suspension in a paraffin cup by gently sucking and blowing 10 times with a siliconized Pasteur-pipette at room temperature. The mixture was immediately transferred to a siliconized slide, covered gently with a siliconized cover-slip and observed for the occurrence of platelet clumping under a regular light microscope $(\times 450)$. The assay for platelet clumping was carried out 3 times and within 6 hours after collecting platelets from different rabbits. The plasma which induced clumping of platelets to the positive or marked positive degree was found to contain the platelet-clumping substance. In some cases the platelet-clumping activity in citrated platelet-rich plasma was examined. The titer of platelet-clumping activity in the plasma and eluate was determined by serial dilution. 


\section{RESULTS \\ I. PLATELET-CLUMPing ACtivity in Plasma SAMPLES}

Platelet-clumping activity was found in 3 of 11 plasma samples from the nontreated rabbits. It was found in 10 of 11 plasma samples from agarinjected rabbits and in all 10 acidified plasma samples from non-treated rabbits. The degree of activity was almost the same with washed platelets in platelet-saline suspension as with unwashed in citrated platelet-rich plasma. The platelet-clumping activity was found even after 8-16 fold dilution of the plasma with physiological saline.

The 10 active plasma samples from agar-injected rabbits (agar-plasma), and all 10 acid-activated plasma samples were used to separate the plateletclumping substance. Eight of 11 plasma samples from non-treated rabbits, with a negative platelet-clumping activity were used as control samples (control plasma).

\section{COLUMN CHROMATOGRAPHY}

\section{Gel Filtration Column Chromatography}

The typical elution curves from Sephadex G-25, G-50 and G-200 columns, representing the protein fraction and the platelet-clumping activity of the plasma preparation, are shown in FIG. 1. Using these columns, the plateletclumping substance was not separated from the main protein peaks. About $90 \%$ of the protein that was applied to the column was recovered. About $90 \%$ of the platelet-clumping activity was recovered from G-25 and G-50, and about $80 \%$ from G-200 column chromatography experiments. The plateletclumping substance was not retained, but rather passed through the G-25 and G-50 columns. In G-200 column chromatography the pletelet-clumping substance was detected at the end of the third protein peak, which was identified as an albumin fraction by paper electrophoresis. Similar results were found using 5 agar-plasma samples and 8 acid-activated plasma samples. On the other hand, the effluents after gel filtration column chromatography of all 5 control plasma samples failed to show clumping activity in any of the fractions.

\section{Ion Exchange Column Chromatography}

The typical chromatographic curve of the proteins from a DEAE-cellulose column and the distribution of the plasma platelet-clumping activity are shown in FIG. 1. In this column chromatography, the platelet-clumping substance was separated from the main protein peaks. About $90 \%$ of the protein was recovered, while $10 \%$ of the platelet-clumping activity was recovered. The platelet-clumping substance was eluted with $1.5 \mathrm{M} \mathrm{NaCl}$ containing phosphate 
Column Chromatography of Rabbit Plasma

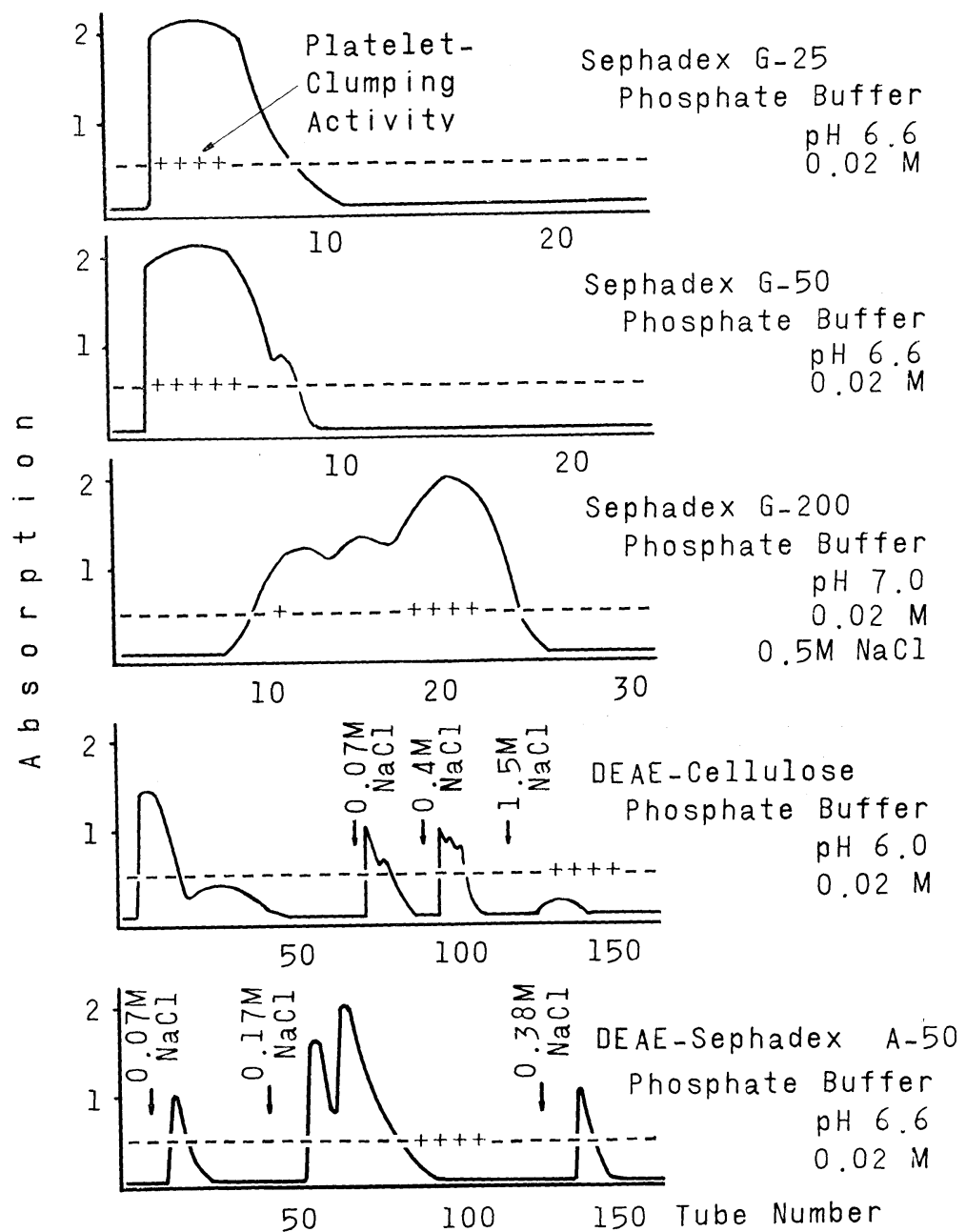

FIG. 1. Column chromatography of rabbit plasma. Plasma samples were obtained from rabbits injected with $0.5 \%$ agar-solution ( $5 \mathrm{ml} / \mathrm{kg} \mathrm{i.v.)} \mathrm{before}$ the collection. The elution curves of the protein fractions are represented by optical density at $280 \mathrm{~m} \mu$. The platelet-clumping activity of the eluates is expressed by + (positive) or - (negative).

buffer, $\mathrm{pH} 6.0$, in the cases of 2 agar-plasma samples and 2 acid-activated plasma samples. The 2 control plasma samples did not show the clumping activity in any of the chromatographic fractions.

\section{DEAE-Sephadex A-50 Column Chromatography}

The typical chromatographic curve from a DEAE-Sephadex A-50 column 
is shown in FIG. 1. In this column chromatography, the platelet-clumping substance was separated from the main protein peaks. The recovery values for protein and platelet-clumping activity were about $90 \%$ and $10 \%$ respectively. The platelet-clumping substance, after eluted with $0.17 \mathrm{M} \mathrm{NaCl}-0.02 \mathrm{M}$ phosphate buffer, $\mathrm{pH}$ 6.6, appeared after the third protein peak. Analysis by paper electrophoresis showed that the first peak of protein is $\alpha$ and $\beta$-globulin, the second peak is haptoglobulin, the third peak albumin; and the last peak $\gamma$-globulin. The platelet-clumping activity was usually detected just after the albumin peak in the cases of 3 agar-plasma samples and 2 acid-activated plasma samples. Two control plasma samples did not show the clumping activity in any of the fractions after DEAE-Sephadex A-50 column chromatography.

\section{ELECTROPHORESIS}

\section{Starch-Block Electrophoresis}

Starch-block electrophoresis was performed on 10 plasma samples from agar-injected rabbits (agar-plasma). After electrophoresis albumin-bound bromphenol-blue was detected in most cases between the $8 \mathrm{~cm}$ - and $9 \mathrm{~cm}$ fraction. The most darkly stained fraction was $8.3 \pm 0.26 \mathrm{~cm}$-fraction (average and standard error in the 10 cases). The platelet-clumping activity was found in the eluates of the fractions between $8 \mathrm{~cm}$ and $11 \mathrm{~cm}$. The fraction which showed the strongest platelet-clumping activity was the $9.6 \pm 0.31 \mathrm{~cm}$-fraction in average of the 10 cases. In 2 of the 10 cases, the platelet-clumping activity was detected in a fraction containing a component of faster mobility than that of albumin and was not detectable in the main albumin fractions. In the other 8 cases the platelet-clumping activity was contaminated by the albumin fractions.

The albumin-bound bromphenol-blue was detected between the $8 \mathrm{~cm}$ - and $10 \mathrm{~cm}$-fractions and the platelet-clumping activity was found in the eluates of the fractions between $9 \mathrm{~cm}$ and $11 \mathrm{~cm}$ after starch-block electrophoresis of 3 acid-activated plasma samples. In 1 of the 3 cases, the platelet-clumping activity was detected in a fraction containing a component of faster mobility than that of albumin but was not found in the albumin fractions.

Starch-block electrophoresis was also performed on 8 control plasma samples. Albumin-bound bromphenol-blue was detected between the $8 \mathrm{~cm}$ and $9 \mathrm{~cm}$-fractions. The most darkly stained fraction was at $8.6 \pm 0.07 \mathrm{~cm}$ in average of the 8 cases. The platelet-clumping activity was also found in the eluates of the fractions between $9 \mathrm{~cm}$ and $11 \mathrm{~cm}$, although the plasma did not show any clumping activity before electrophoresis. The strongest plateletclumping activity was found in the $9.6 \pm 0.14 \mathrm{~cm}$-fraction in average. In 3 of the 8 cases the platelet-clumping activity was found in a fraction with a faster mobility than that of albumin. In the case of the 3 plasma samples 
from non-treated rabbits which showed platelet-clumping activity, albumin was found in the $9.0 \pm 0.00 \mathrm{~cm}$-fraction and the platelet-clumping activity in the $10.3 \pm 0.31 \mathrm{~cm}$-fraction in average.

In any of these plasma samples, an anticoagulation activity, which originated from added heparin, was found in the fractions with faster mobility than that of the platelet-clumping substance. It was found usually in the eluates of the fractions between $15 \mathrm{~cm}$ and $18 \mathrm{~cm}$ (average: $16.9 \pm 0.21 \mathrm{~cm}$ ). The typical starch-block electrophoretic pattern for the albumin-bound bromphenol-blue and for the platelet-clumping activity and the anticoagulation activity in plasma is shown in FIG. 2.

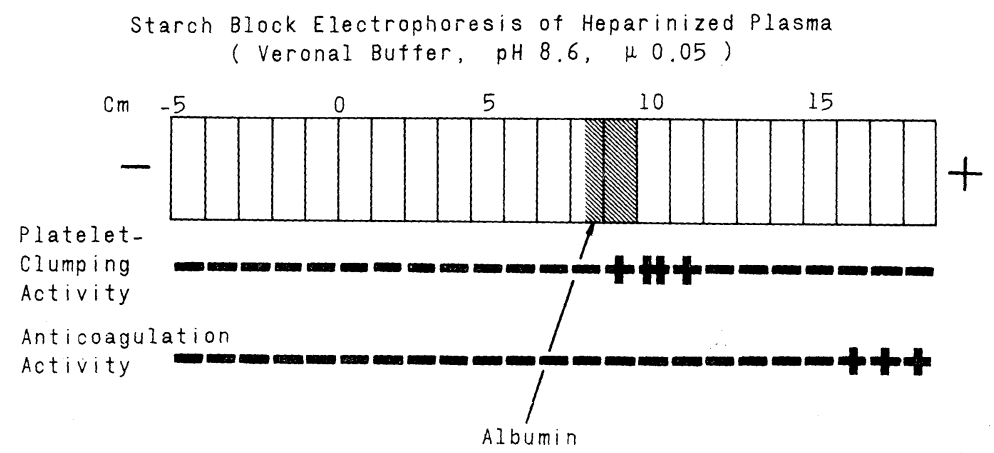

FIG. 2. Starch block electrophoresis of rabbit plasma. Bromphenol bluestained albumin zone is shown as shadowed area; the platelet-clumping activity and the anticoagulation activity are shown as + or - . 0 means starting line.

\section{Immunoelectrophoresis}

To clarify some possible relationship between plasma proteins, especially albumin and the platelet-clumping substance, immunoelectrophoresis was performed on the eluates from starch-block electrophoretic fractions of 2 control plasma samples and 4 agar-plasma samples. The typical immunoelectrophoretic patterns for the albumin-precipitation line and for the platelet-clumping activity of the eluate are shown in FIG. 3. The eluate of the $7 \mathrm{~cm}$-fraction showed a marked precipitation line against albumin but not against plateletclumping activity. The eluates of the $8 \mathrm{~cm}$ - and $9 \mathrm{~cm}$-fractions with their marked platelet-clumping activity exhibited a moderately dense precipitation line against albumin. The eluate of the $10 \mathrm{~cm}$-fraction with platelet-clumping activity gave no precipitation line. In all the 6 cases similar results were obtained and the clumping activity was found in one or more fractions containing albumin and/or component of faster mobility than that of albumin (pre-albumin fraction). 


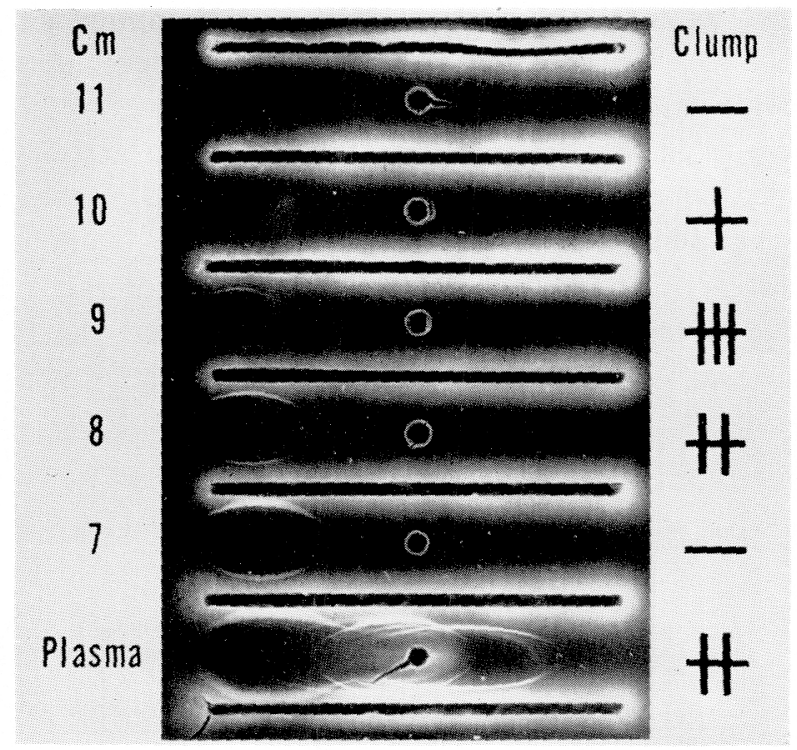

FIG. 3. Immunoelectrophoresis on the eluates from starch-block electrophoretic fractions of rabbit plasma. Goat antiserum to rabbit serum was used as the antibody. The numbers of the left side indicate the fractions from which the eluate was collected. In the right side, the grades of plateletclumping activity are shown. The bottom section shows the electrophoretic pattern of rabbit plasma as a control. White precipitation lines against albumin are demonstrated with the fractions of 9,8 and 7 , indicating the difference between the albumin-precipitation line and the clumping activity.

\section{SOME PROPERTIES OF THE PLATELET-CLUMPING SUBSTANCE}

The active preparations isolated from plasma by starch-block electrophoresis, DEAE-cellulose or DEAE-Sephadex A-50 column chromatography, were dialyzed against running water for 72 hours. These eluates induced platelet-clumping not only in platelet-saline suspension but also in citrated platelet-rich plasma even after the dialysis. The platelet-clumping activity was neither destroyed by heating $\left(100^{\circ} \mathrm{C}, 15\right.$ minutes $)$ nor interfered with by the addition of $1 \%$ EDTA in final concentration. These failed to demonstrate any distinct peak around $260 \mathrm{~m} \mu$.

\section{DISCUSSION}

Though the chemical structure of the platelet-clumping substance is still obscure, the present experiments indicate that the eluates from DEAE-cellulose or DEAE-Sephadex A-50 column chromatography and starch-block electrophoresis have the ability to clump platelets in a manner similar to that found 
in plasma collected from agar-injected rabbits $^{2)}$ and the acid-activated plasma ${ }^{32}$. It was not dialyzable. These results suggest that the active platelet-clumping substance may be of high molecular weight and acidic in nature.

After electrophoresis of plasma, coagulation factors I, II, V,VII, VIII, IX, $\mathrm{X}, \mathrm{XI}, \mathrm{XII}$ and XIII were detected in globulin fractions ${ }^{10)}$. BRINKHOUs et al. ${ }^{4,11)}$ reported that thrombocyte agglutinating factors are detectable in crude globulin fractions and destroyed by heating for 10 minutes at $56^{\circ} \mathrm{C}$. ADPcofactor, reported by BORN et al.5), is present in euglobulin fractions and is not heat stable. Plasma co-factor, reported by DEYKIN et al. ${ }^{12}$, is present in the crude globulin fractions. These substances require calcium or magnesium ions, or ADP in order to clump washed platelets. Recently BARNHART et al. ${ }^{13)}$ reported that a production of fibrinogen degradation (FSP) actively aggregated platelets and NIEWIAROWSKI ${ }^{14)}$ showed an early fibrinogen degraded product (FDP) to aggregate platelets. These experiments were carried out using platelet-rich plasma. The platelet-clumping substance observed by the authors clumped washed platelets even with 1\% EDTA added and was separated from the anticoagulation activity by the starch-block electrophoresis. It was detected in the pre-albumin fraction by starch-block electrophoresis and did not show any precipitation line against plasma proteins in the immunoelectrophoretic findings. The platelet-clumping substance present in plasma was lost by heating for 30 minutes at $56^{\circ} \mathrm{C}^{3)}$, but once it was isolated from the plasma proteins by column chromatography or electrophoresis, its activity was not destroyed by heating. It showed no peak at $260 \mathrm{~m} \mu$. It is concluded, therefore, that a clear difference exists between the substance observed by the authors and ADP or the other plasma factors reported.

In the present experiments the platelet-clumping activity was found in electrophoretic samples from albumin or pre-albumin fractions even when non-treated rabbit plasma which showed no platelet-clumping activity was applied. The starch-block electrophoresis may activate the platelet-clumping substance or remove some inhibitor in the plasma as in the case of acidification $^{3)}$.

In 1961, GAARDER and his associates ${ }^{15)}$ found the aggregation of platelets induced by ADP. For the last few years a number of studies have developed concerning the effect of ADP and the other low molecular weight compounds on platelets. However, the platelet-clumping substance described by the authors in $1958^{1)}$, differed from these described products. In the present experiment, the platelet-clumping substance was separated from plasma proteins and its chemical property might be of high molecular and acidic in nature. It is very interesting that abundant acid mucopolysaccharide consists in surface coat of platelets ${ }^{16}$. It may be related to clumping of platelets. Recently DAvEY and ESNOUF ${ }^{17)}$ separated a substance from the venom of the Okinawan pit viper (Trimeresurus okinavensis) that causes the aggregation 
of human platelet. The purified venom fraction is a protein-polysaccharide. The structure of the substance observed by the authors may be partially similar to the above mentioned substance, however, the platelet-clumping substance was found in plasma collected from the rabbits injected with high molecular weight substance or adrenaline ${ }^{2)}$ and from humans with thrombosis, infection or tissue destruction ${ }^{6}$. It was also found in plasma after the weak acidification which could be observed in ischemic or inflammatory tissues locally ${ }^{32}$. These results may suggest that a precursor of the platelet-clumping substance is present in plasma and activated by inflammatory or ischemic responses. The result obtained from the present experiment implies the importance of further research, suggesting the existence of a phylogenetically old mechanism ${ }^{18)}$ which counteracts the bleeding regardless of fibrinogen fibrin system.

\section{SUMMARY}

The heparinized plasma collected from 11 non-treated, 10 agar-injected rabbits and 10 heparinized acidified plasma samples were eluated by column chromatography (G-25, G-50, G-200, DEAE-cellulose and DEAE-Sephadex A-50) or treated by starch-block electrophoresis. Using column chromatography fo G-25, G-50 or G-200, the platelet-clumping activity was found in the protein fractions. Using chromatography of DEAE-cellulose, the platelet-clumping activity was eluated in $1.5 \mathrm{M} \mathrm{NaCl}$ containing phosphate buffer, $\mathrm{pH}$ 6.0. Using chromatography of DEAE-Sephadex A-50, it was eluated in $0.17 \mathrm{M} \mathrm{NaCl}$ containing phosphate buffer following the albumin fraction. Using starchblock electrophoresis, the platelet-clumping activity was found in the albumin band and/or in fractions containing a component of faster mobility than that of albumin (pre-albumin fraction). Platelet-clumping activity was also detected in electrophoretic extracts of plasma from non-treated rabbits which, prior to electrophoresis, had not shown any platelet-clumping activity. Starchblock electrophoresis may serve to activate the platelet-cluming substance or remove some inhibitor in the plasma. The eluates collected through the above mentioned procedures clumped platelets not only in citrated plateletrich plasma but also in platelet-saline suspension without calcium ions. It was not dialyzable against running water for 72 hours; it was heat-stable at $100^{\circ} \mathrm{C}$ for $15 \mathrm{~min}$; it failed to demonstrate a peak around $260 \mathrm{~m} \mu$ in the ultraviolet absorption test.

The authors wish to thank Dr. N. Katsura, Dr. S. Hosaki, Dr. K. OhtA and Mr. $\mathrm{K}$. ABE for invaluable suggestions and experimental assistance and also to Professor $\mathrm{M}$. Yokoy Ama, University of Hawaii for the immunoelectrophoresis. 


\section{REFERENCES}

1) Shimamoto, T., Yamazaki, H., Sagawa, N., Iwahara, S., Konishi, T. and MAEzAWA, H.: Effect of bacterial endotoxin on platelets and release of serotonin (5-hydroxytryptamine). II. Appearance of platelet-agglutinating substance and serotonin in the plasma of rabbit by administration of bacterial endotoxin. Proc. Japan Acad., $34:$ 450, 1958.

2) Yamazaki, H., Shimamoto, T., Murase, H. and Shimamoto, T.: Appearance of platelet-clumping substance in plasma of rabbit after the intravenous injection of agar-solution, bacterial endotoxin or adrenaline. Blood, 30:792, 1967.

3) Yamazaki, H., Murase, H., Shimamoto, T. And Shimamoto, T.: Appearance of platelet-clumping substance after acidification of plasma. Blood, 31: 348, 1968.

4) Brinkhous, K.M., LeRoy, E.C., Cornell, W.P., Brown, R.C., Hazlehurst, J.L. AND VENNART, G.P.: Macroscopic studies of platelet agglutination: Nature of thrombocyte agglutinating activity of plasma. Proc. Soc. Exper. Biol. \& Med., $98: 379,1958$.

5) Born, G.V.R. AND CROss, M.J.: Effects of inorganic ions and of plasma proteins on the aggregation of blood platelets by adenosine diphosphate. J. Physiol., 170 : 379, 1964.

6) Yamazaki, H., Murase, H., Shimamoto, T. And Shimamoto, T.: Appearance of platelet-clumping substance in plasma from humans with thrombosis, infection or tissue destruction. Proc. Japan Acad., $44:$ 1066, 1968.

7) Kunkel, H.G. And Slater, R.J.: Zone electrophoresis in starch supporting medium. Proc. Soc. Exper. Biol. \& Med., 80: 42, 1952.

8) Scheidegger, J.J.: Micromethod of immunoelectrophoresis. Internat. Arch. Allergy, $7:$ 103, 1955.

9) Aronsson, T. And Grönwall, A.: Improved separation of serum proteins in paper electrophoresis-new electrophoresis buffer. Scand. J. Clin. \& Lab. Invest., $9: 338,1957$.

10) Sirridge, M.S.: Laboratory evaluation of hemostasis, Lea and Febiger. Philadelphia, 1967, page 7.

11) Mason, R.G., LeRoy, E.C. And Brinkhous, K.M. : Natural thrombocyte agglutinating system: Thrombocyte agglutinating factors ( $\mathrm{TAg}$ and $\mathrm{TAg}^{\prime}$ ) in plasma, in Blood platelets. Little, Brown and Co., Boston, 1961, page 111.

12) Deykin, D., Pritzker, C.R. And Scolnick, E.M.: Plasma co-factors in adenosine diphosphate-induced aggregation of human platelet. Nature, 208: 296, 1965.

13) Barnhart, M.I., Cress, D.C., Henry, R.L. And Riddle, J.M.: Influence of fibrinogen split products in platelet. Thromb. Diath. Haemorrhag., 17: 78, 1967.

14) Niewiarowski, S.: Physiologic implications of fibrinolysis. XII. Congress International Society of Hematology, 1968. Sept. New York.

15) Gaarder, A., Jonsen, J., Laland, S., Hellem, A. And Owren, P.A. : Adenosine diphosphate in red cells as a factor in the adhesiveness of human blood platelets. Nature, $192: 531,1961$.

16) BeHNKe, O.: Electron microscopic observations on the membrane system of the rat blood platelet. Anat. Rec., 158: 121, 1967.

17) Davey, M.G. And Esnouf, M.P.: The isolation of a component of the venom of Trimeresurus okinavensis that causes the aggregation of blood platelets. Biochem. J., $111: 733,1969$.

18) Maupin, B.: Blood platelets in man and animals. Pergamon Press, Oxford, 1969, page 516. 